\title{
Fiscal Research on Establishing and Perfecting the Agricultural Ecological Compensation Mechanism
}

\author{
Biyun Xiao ${ }^{1}$ \\ ${ }^{1}$ Fuzhou University of International Studies and Trade, Fuzhou, Fujian Province, China
}

Keywords: fiscal policy; agricultural ecological compensation; ecological compensation mechanism

\begin{abstract}
Agricultural ecological compensation is an important regulation method to achieve the protection of ecological environment resources, as well as an institutional arrangement to promote the sustainable development of agriculture. The public product attributes and external attributes of the ecological environment determine the inevitability and necessity of government intervention in agricultural ecological compensation. This paper analyzed the problems existing in China's agricultural ecological compensation system from the perspective of public finance and proposed relevant countermeasures and suggestions for improving China's agricultural ecological compensation mechanism.
\end{abstract}

\section{Introduction}

Agricultural ecological compensation is the use of fiscal and other economic means to incentivize the farmers to protect, improve and restore agricultural ecosystem service functions and adjust the interest relationship between agricultural ecological beneficiaries, service providers and vandals, which can internalize the external costs generated by agricultural production activities and ensure the institutional arrangements for sustainable agricultural development[1]. The government plays a leading role in agricultural ecological compensation. As the main policy means for the government to implement ecological compensation, the government should incorporate the improvement of agricultural ecological compensation policy into the public finance expenditure category.

\section{Theoretical Basis of Agricultural Ecological Compensation from the Perspective of Public Finance}

At present, there are various ecological compensation theories that discuss the rationality of ecological compensation for the use of environmental resources from different perspectives. The theories studying agricultural ecological compensation from the perspective of public finance are listed as the following.

\subsection{Theory of Public Product.}

Public products are non-competitive and non-exclusive. The agro-ecological environment has the characteristics of public products and anyone can benefit from a good ecological environment. Thus, some consumers in certain eco-environment will only pay attention to their immediate interests, excessively use the ecological environment and seriously damage the agricultural ecosystem while the interests of the other community members are affected. At the same time, in the process of agro-ecological environment protection, the others can enjoy the benefits brought about by the improvement of the ecological environment without any effort. In the absence of effective incentives, few people are willing to carry out ecological environmental protection. Therefore, Theory of Public Product determines that in the agricultural ecological compensation, only the government can be in the dominant position and implement it through fiscal transfer payments [2].

\subsection{Spillover Effect.}

Externalities are divided into positive externalities and negative externalities. Ecological 
environmental protection has positive externalities. Therefore, it is very difficult for people to consciously maintain a good ecological environment and cause "market failure". At the same time, the ecological environmental pollution has negative externalities. In the process of development and utilization of agricultural environmental resources, due to unreasonable development and environmental damage caused by environmental pollution, the interests of other stakeholders and the society are damaged but they do not bear the cost. Therefore, it is necessary for the government to intervene to compensate for market failures and to compensate for the protection of resources and the environment. The developers should bear the costs of social and ecological environment caused by the unreasonable development and environmental pollution.

\subsection{Theory of Fiscal Decentralization.}

Theory of Fiscal Decentralization puts forward that national public goods can benefit all members of the society. It should be provided by the central government. Local public goods are available to the residents of the jurisdiction and need to be provided by local governments at all levels. Eco-environmental protection can benefit all members of society. It is a nationwide public good and the central government must play the leading role. On this basis, the central government must also give local governments more fiscal power to the exercise autonomy, so that local governments have more funds and energy to provide more efficient work in ecological protection and construction and jointly realize the sustainable development of the agricultural ecological environment in China.

\section{Problems Existing in China's Agricultural Ecological Compensation Mechanism}

Fiscal policy has played an important role in the construction and improvement of the ecological environment. However, there are still many problems in China's fiscal support for agricultural ecological compensation mechanism.

\subsection{Fiscal powers of various levels of government are not matched.}

The focus of China's tax-sharing reform is on the division of fiscal power and it does not clearly define the central and local governments' ecological compensation powers and fiscal powers, resulting in large contrast between the distribution system of central and local governments' fiscal and taxation. As part of the nationwide ecological service, it should be borne by the central government's fiscal expenditure. However, the central government will assume the responsibility for environmental protection and ecological restoration projects. The inequality of income and expenditure responsibilities, coupled with regional competition and other factors, will lead to deviations in the governance of the local government. It will be even more dependent on local socioeconomic development indicators and ignore the protection of agro-environmental environment. Those affiliated to regional eco-services should be shared by the fiscal expenditures of local governments at all levels in the region. However, local governments in certain regions do not fulfill their responsibility, leading to the loss of ecological functional areas that need protection and the deterioration of the ecological environment.

\subsection{The fiscal transfer payment system is not standardized.}

At present, China's ecological compensation mainly adopts a vertical transfer payment model, which can make the ecological and environmental protection engineering funds in place with high efficiency. But it has limited effect on the stability of local fiscal capacity. Most regions in China that undertake ecological services are also often ecologically fragile areas and impoverished areas. They will not consume limited fiscal resources and energy to provide ecological services. Under the current fiscal transfer payment system, the fiscal gap between ecological compensation regions and developed regions or beneficiary regions has been extended and expanded, even if the fiscal resources of wealthy areas are transferred from the higher levels of government to poverty-stricken areas through redistribution. It is still difficult to directly reflect the symmetry of the cost-benefit of some public products that have externalities. Horizontal fiscal transfer payment is a method of using ecologically beneficial areas to directly transfer payments to ecological construction and protection 
areas. It plays an important role in improving the current fiscal transfer payment system. However, at present, our country lacks the fiscal transfer payments between horizontal governments at the same level.

\subsection{Existing ecological compensation tax system has obvious defects.}

As a means of fiscal compensation, ecological compensation tax plays an important role in the field of ecological compensation. However, the sewage charge system introduced in 1978 was due to the low sewage charges. The treatment cost of pollutants was about $50 \%$ higher than the sewage charges. Thus, some polluters would rather pay a more cost-effective sewage charge instead of carrying out environmental pollution purification and treatment. At present, the scope of resource tax collection is relatively narrow. Water resources, as an important natural resource of the country, was firstly piloted in Hebei Province in 2016 to reform taxation of water resources. However, the agricultural water, especially agricultural irrigation water, which plays an important role in national food security, has never collected water resources fees. At the same time, the design of the tax system does not reflect the issues related to environmental protection, such as how to deal with pollution after the exploitation of resources.

\subsection{Scientific agricultural ecological compensation standards are lacking.}

The determination of the amount of compensation for agricultural ecological environment in China has not taken into account the differences in regional socio-economic levels, as well as the types of agricultural ecological environment. For example, in the national compensation for returning farmland to forests, the national unified standard for cash subsidies per acre for returning arable land per year is 20 yuan. And the national uniform standard for seedlings and afforestation fees is 50 yuan per mu for afforestation of abandoned farmland and uncultivated wasteland in suitable hills. The grain subsidy standard for farmer households with farmland conversion is divided into the Yellow River and Haihe River Basin and the Yangtze River and Huaihe River basin areas in the country. The subsidy standards for the two large regions are 100 kilograms and 150 kilograms of cultivated land per mu. The compensation method has dampened the enthusiasm of farmers and other agricultural ecological entities for environmental protection of agricultural ecology and has not played the practical role of compensation.

\section{To Establish and Improve the Fiscal Mechanism of Agricultural Ecological Compensation}

\subsection{To build a multi-level agricultural fiscal compensation system.}

The establishment of multi-level compensation capital can provide incentives for local environmental protection. And at the same time, it forms a multi-layered interaction mechanism [3].

Central ecological compensation mechanism. The construction of the central ecological compensation mechanism is dominated by the central government. The fiscal capital arranged by the central government are used for agricultural pollution and other issues related to the ecological environment in the country. The central ecological compensation mechanism mainly protects, restores and compensates the ecological environment in the form of general transfer payments and special transfer payments. As far as China's current basic situation is concerned, the key to constructing a central ecological compensation mechanism is to perform the environmental protection duties of the central government, formulate ecological strategies, guidelines and plans, guide the country and urge local governments to actively perform environmental responsibilities and implement ecological compensation projects.

Provincial ecological compensation mechanism. Provincial finance is the main part of provincial ecological compensation transfer payment. It mainly protects, restores and compensates the ecological environment in local areas through tax incentives, fiscal subsidies, government fund and paid use of resources. The provincial government should set up local compensation capital in the region according to the socio-economic development of each province and the actual situation of the ecological environment, use the factor method and the coefficient method to raise the capital needed 
for the transfer of the province's fiscal transfers, and reasonably determine the capital required. The direction and focus of investment are based on the principle of transfer payments, it should clarify the scope of use of ecological compensation capital and promote ecological environmental protection.

Municipal and county-level ecological compensation mechanism. The construction of the municipal and county-level ecological compensation mechanisms is dominated by the municipal and county governments and managed and coordinated by the provincial government. The provincial government can make vertical compensation to the municipal and county governments through subsidies for food transfers, loss fees and work expenses, optimize the allocation and use capital from various sources in an integrated manner to integrate agricultural development, poverty alleviation, water and soil conservation and some other compensation measures are combined [4]. Municipal and county-level governments should arrange project capital in a rational and reasonable manner and clearly stipulate inclining ecological and environmental protection projects. They mainly increase support for ecological compensation through measures such as tax incentives and fiscal subsidies.

\subsection{To establish a crisscross fiscal transfer payment system.}

To improve vertical ecological compensation fiscal transfer payment system. At present, the return of tax revenue in the annual fiscal transfer payment system not only does not play a role in reducing the fiscal resource gap among the regions, but also further exacerbates the gap in fiscal revenue among local governments. Therefore, it is possible to ban the return of taxes, adopt regular fiscal transfer payments and promote the rationalization of the fiscal transfer payment system. In addition, it is also necessary to optimize general transfer payments and choose factors that are not easily subject to human control and comprehensive coverage to measure local fiscal revenues and expenditures, thus playing a fiscal balance. At the same time, in view of the huge amount of capital and energy required for ecological compensation and its slow performance, it is necessary to set up special fiscal capital to increase fiscal compensation for ecological compensation and increase investment in ecological construction and ecological services.

To establish ecological compensation horizontal fiscal transfer payment system. The horizontal transfer payment system of ecological compensation is a useful supplement to China's vertical transfer payment. Through the establishment of a regional agricultural ecological compensation fiscal transfer payment fund, agricultural ecological beneficiary areas will have to pay corresponding compensation capital to provide agricultural ecological service provision areas. This will not only give full play to the leading role of the central government in ecological compensation, but also enable the integration of all forces to compensate regional fiscal resources. These can make up for the shortage of capital generated by local governments due to lack of fiscal resources, so that ecological beneficiaries and providers will become more reasonable in the sharing and enjoyment of costs and benefits, mobilize the protection of agricultural ecological environment in various regions and form the interdependence and mutual restraint relationship between ecological compensation and environmental protection.

\subsection{To improve the ecological compensation tax system.}

To reform the current ecological compensation tax system. For the current sewage charging system, economic stimulus measures and administrative punishment methods can be combined. Excessive levying of punitive expenses on the polluters' excessive discharge of pollutants and punitive expenses should be significantly over-contaminated, so as to force the polluters to reduce the discharge of pollutants such as fertilizers and pesticides in agricultural production. In terms of the resource tax, the government should expand the scope of collection. It is necessary to levy agricultural water resources tax, forest resource tax and grassland resource tax in a timely manner, adhere to the principle of special capital for special usage to vigorously promote water conservation, prevention and control of pollution and protect the agricultural ecological environment. In the exploitation of resources, production, product consumption and waste disposal and other aspects, the appropriate taxes should be set up to achieve reasonable development and utilization of resources. In terms of urban land use tax, tax incentives should be applied to enterprises that produce regulated agricultural products. 
To collect agricultural environment tax. The unreasonable use of production materials and pollutants discharged from livestock and poultry farms are important causes of agricultural non-point source pollution. The government can collect and reduce agricultural environmental taxes for different situations in which enterprises develop, use and protect the agricultural ecological environment. For example, for the enterprises that produce and use production materials which meet the ecological requirements and the intensive livestock and poultry farms, special tax for the prevention and control of agricultural non-point source pollution can be collected for the prevention and control of agricultural environmental pollution [5]. The enterprises that produce and use production materials that do not meet ecological requirements shall be levied on environmental pollution taxes. In this way, it can promote the enterprises to bear the corresponding economic costs, thus limiting the $m$ to give up or converge on the pollution and waste of environment and resource. At the same time, tax incentives have been formulated to encourage the enterprises to actively produce and use production materials that meet statutory requirements.

\subsection{To establish a compensation system for agricultural ecological protection.}

To set reasonable compensation standards. Ecological compensation standards are the core of ecological compensation [6]. The determination of agricultural ecological compensation standards should consider the cost paid by the ecological protectors for the protection of the ecological environment and the opportunity cost lost due to the protection of the ecological environment. In specific practices, differential compensation standards should be implemented. Based on actual conditions in different regions, comprehensive consideration will be given to factors such as the fiscal capacity of different regions, ecological damage and the willingness of the compensation subject to compensate, etc. Based on the output capacity of agricultural ecological products, the ecosystem service function value method, the opportunity cost method and market method and other methods of calculation will be improved. At the same time, according to the ecological protection of the agricultural ecological compensation region and the phased characteristics of social and economic development, it is necessary to carry out dynamic verification with times.

To scientifically plan the compensation scope. Given the limited economic strength of the country, the scientific plan of compensation scope is particularly important. The agricultural ecological compensation projects that are to be implemented preferentially across the country should be projects that have significant benefits to the agricultural ecological environment and are easy to be implemented [7]. For example, returning farmland to forests has made tremendous contributions to the ecological environment and is beneficial to consolidate the results of returning farmland to forests. It should be listed as a priority compensation program. Projects such as comprehensive utilization of straw resources, subsidies for farmland protection and quality improvement and recycling of agricultural inputs wastes can not only save resources and reduce pollution, but also facilitate implementation. Therefore, it should also be listed as priority compensation projects. When arranging priority compensation projects, it is also necessary to adapt them to local conditions. For example, in the eastern developed regions of China, the problem of agricultural pollution is quite serious. Therefore, even if it is very difficult to prevent and control agricultural pollution, it should also be considered as a key project of ecological compensation for the reduction of chemical fertilizers and pesticides. In the western regions, grassland degradation, soil erosion, land desertification and other phenomena are more serious. Measures such as comprehensive management of small watersheds and fallow and no-tillage have obvious environmental benefits and should be listed as key compensation projects.

To select the appropriate compensation method. There are currently four major types of ecological compensation methods in China, that is, capital compensation, physical compensation, policy compensation, technology and intellectual compensation. The capital compensation can quickly compensate farmers in the compensation area for their contributions to ecological services. Therefore, it is the main method of compensation. However, this direct compensation method cannot fundamentally promote the improvement of environmental awareness and skills of farmers in the compensation area. As an effective supplementary form of capital compensation, policy 
compensation and intellectual technology compensation can provide various preferential treatment, such as preferential tax treatment for the compensation zone, as well as intellectual services, such as free training specialized technology for the compensation, which can effectively improve the sustainable development capacity of agriculture. Therefore, the method of agro-ecological compensation must combine multiple compensation methods in light of actual conditions to promote diversification of compensation methods.

\section{Conclusion}

Fiscal policy instruments still have problems such as the incompatibility of fiscal powers between governments at all levels, the non-standard fiscal transfer payment system, the obvious flaws in existing ecological compensation tax systems and the lack of scientific agricultural ecological compensation standards. Therefore, in order to further promote the healthy development of China's agricultural ecological compensation work, it is necessary to construct multi-level agricultural fiscal compensation system at the central, provincial, municipal and county levels, establish crisscross fiscal transfer payment system and improve ecological compensation tax system and establish the agricultural ecological protection compensation standards system to improve China's agricultural ecological compensation mechanism.

\section{References}

[1] J. S. Jin. Research on Agricultural Ecological Compensation in China [D]. Changchun: Jilin University, 2011.

[2] Z. C. Lv. Study on Fiscal Transfer Payment System between Governments Based on Ecological Compensation [D]. Lanzhou: Northwest Normal University, 2013.

[3] F. Gao. Reflections on Fiscal Policy of Ecological Compensation Mechanism [J]. China State Finance, 2012 (12): 75.

[4] F. Zhang \& J. Cao. The Institutional Dilemma and the Construction of the Harmonious Mechanism of Interest of Agricultural Ecological Compensation in China [J]. Research of Agricultural Modernization, 2010 (09): 538-542.

[5] N. W. Wei. Agricultural Non-point Source Pollution Control and Fiscal Policy Choice [J].Sub-national Fiscal Research, 2013 (12): 55-58.

[6] X. You. Ecological Compensation Theory and Practice Innovation Research [J]. Journal of Inner Mongolia Agricultural University, 2011 (5): 90-94.

[7] Z. M. Liu. Analysis on the Restricting Factors of Agricultural Ecological Compensation Development in China and Its Path Selection [J]. Academic Exchanges, 2014 (03): 99-104. 